\title{
Method development and validation of ursodiol and its major metabolites in human plasma by HPLC-tandem mass spectrometry
}

This article was published in the following Dove Press journal:

Clinical Pharmacology:Advances and Applications

\section{Márcio Cardoso Pinto Danilo Chorfi Berton \\ Alexandre Cavenatti de Oliveira \\ Carolina Martins Lazaro Silvana Aparecida Calafatti Carandina}

Pharmacology Department (UNIFAG), Universidade São Francisco, Bragança Paulista, SP, Brazil
Correspondence: Márcio Cardoso Pinto Pharmacology Department (UNIFAG), São Francisco University (Universidade São Francisco), Bragança Paulista College, São Francisco de Assis Avenue, Jardim São José, I2916-900, Bragança Paulista, SP, Brazil

Tel +55 II 24548405

Fax +55 II 9963। 583I

Email marcio.pinto@usf.edu.br
Background: Ursodeoxycholic acid (UDCA) and its metabolites tauroursodeoxycholic acid (TUDCA) and glycoursodeoxycholic acid (GUDCA) have been the subject of several pharmacological studies. The objective of this study was to develop an innovative method of quantification by HPL-tandem mass spectrometry (LC-MS/MS), with a lower cost and suitable, for application in bioequivalence studies.

Methods: The procedure involved liquid-liquid extraction for quantification of UDCA/ GUDCA and precipitation extraction for TUDCA, using deuterated substances as internal standards (ISs) and Phenomenex Luna $250 \times 4.6 \mathrm{~mm} 5 \mu \mathrm{C}_{18} 100 \mathrm{~A}$ column. The mobile phase

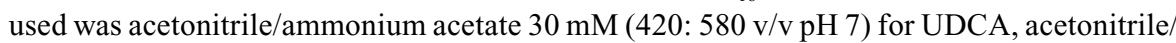
ammonium acetate $10 \mathrm{mM} /$ ammonium hydroxide (400:600: $0.5 \mathrm{v} / \mathrm{v} / \mathrm{v} \mathrm{pH} \mathrm{9)} \mathrm{for} \mathrm{GUDCA,}$ and acetonitrile/ammonium acetate $10 \mathrm{mM}$ (570: $430 \mathrm{v} / \mathrm{v} \mathrm{pH} \mathrm{7)} \mathrm{for} \mathrm{TUDCA.} \mathrm{Ions} \mathrm{were}$ monitored by the electrospray ion source (ESI) mass spectrometer, operating in a negative ionization mode. Compound determination was performed by LC-MS/MS system using a calibration curve of $15-10,000 \mathrm{ng} / \mathrm{mL}$ for UDCA/GUDCA and 5-500 $\mathrm{ng} / \mathrm{mL}$ for TUDCA. The method was developed and validated according to the Brazilian National Health Surveillance Agency (ANVISA) of Brazil norms harmonized with the main international guidelines as a prerequisite for conducting in vivo study in human volunteers.

Results: The method did not present matrix effect and residual effect, showing to be selective for studied molecules, with adequate accuracy and precision. In addition, the method was considered sensitive presenting a coefficient of variation less than $20 \%$ for the lower limit of quantification of each compound.

Conclusion: This method can be applied in bioequivalence studies to determine ursodiol and its metabolites reproducibly, simply, and effectively with the use of readily accessible analytical materials and instrumentation.

Keywords: ursodeoxycholic acid, glicoursodeoxycholic acid, tauroursodeoxycholic acid, bioequivalence, LC-MS/MS

\section{Introduction}

Ursodeoxycholic acid or ursodiol ( $3 \alpha, 7-\beta$-dihydroxy-5- $\beta$-cholanic acid [UDCA] $)$ is a bile acid that naturally occurs in small amounts in human plasma. It acts physiologically in the regulation of cholesterol, reducing the rate at which the intestine absorbs and synthesizes these molecules. ${ }^{1,2}$ For this reason, UDCA is used pharmacologically in pathologies where there is dysfunction of that regulation, such as for the treatment of gallstones formed by cholesterol, postcholecystectomy syndrome, primary biliary cirrhosis, dyskinesias, hypercholesterolemia and hypertriglyceridemia, cholestasis, and chronic hepatitis, among others. ${ }^{3-6}$ 
After ingestion, UDCA passes through the liver where, by amidation processes, it is conjugated with glycine or taurine, originating from its main metabolites glycoursodeoxycholic acid ( $(\mathrm{N}-[(3 \alpha, 5 \beta, 7 \beta)-$ 3,7-dihydroxy-24-oxocholan-24-yl]-glycine

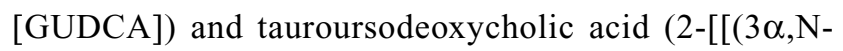
( $3 \alpha, 7 \beta$-dihydroxy- $5 \beta$-cholan-24-oyl)-taurine [TUDCA]). After being secreted into the hepatic bile ducts, these conjugates are concentrated in the gallbladder and expelled into the duodenum, where their pharmacological functions will be performed. ${ }^{4,5,7}$ Therefore, it is necessary to quantify both the unaltered drug (UDCA) and its metabolites (TUDCA and GUDCA) in bioequivalence studies. ${ }^{8}$ The chemical structures of these compounds are presented in Figure 1.

There are countless researches on new applications of UDCA nowadays, and so far, results have demonstrated that this drug is able to delay the progression of cataract in rats with diabetes induced by hyperglycemia due to its potential antioxidant action; ${ }^{9}$ the UDCA has also been shown to promote healing in the epithelium of the colonic mucosa of rats and has been identified as a natural regulator of that process; ${ }^{10}$ the previous studies have also shown that the ursodiol metabolite TUDCA promotes decreased insulin resistance in the liver, skeletal muscle, and adipose tissue in obese rats, and similar results have been obtained in humans; ${ }^{11}$ UDCA has shown anti-inflammatory effects and promoted functional recovery in rats with spinal cord injury; ${ }^{6}$ male rats with cholestasis were treated with UDCA and it led to the prevention of the development of obesity associated with hypertension in their male litters, ${ }^{11}$ among several other studies. The existence of recent research for treatment and control of several pathologies either associated with or not associated with liver problems shows that
UDCA has broad therapeutic potential and could well become the target of pharmacological discoveries. This makes the development of generic UDCA drugs especially attractive because it brings with it the possibility of new drug therapies at a lower cost to the population.

Several analytical methods have been developed for determining bile acids in biological fluids, among them the UCDA and its metabolites, each one with its own particularities. ${ }^{3,8,13}$ The development of a suitable and simple method in LC-MS/MS (HPLC-tandem mass spectrometry) for UDCA, GUDCA, and TUDCA determination could be useful in enabling an understanding of the original compound's metabolism as well as in obtaining new generic drugs that are more accessible and less costly for the population and the pharmaceutical industry.

This study aimed to develop a new, efficient, and simple methodology for quantification of ursodiol and its main metabolites in low concentrations in human plasma through the use of LC-MS/MS methodology, thereby enabling its application in bioequivalence/bioavailability studies. In addition, a full validation of the method was performed in accordance with the guidelines of the Brazilian National Health Surveillance Agency (ANVISA), which are harmonized with the main international guidelines and are a prerequisite for conducting an in vivo study in human volunteers. $^{14}$

\section{Materials and methods Materials}

The UDCA reference standard was purchased from British Pharmacopeia (Queen's Road, Teddington, UK), and its metabolites, TUDCA sodium salt and GUDCA, were purchased from Synfine Research (Ontario, Canada),

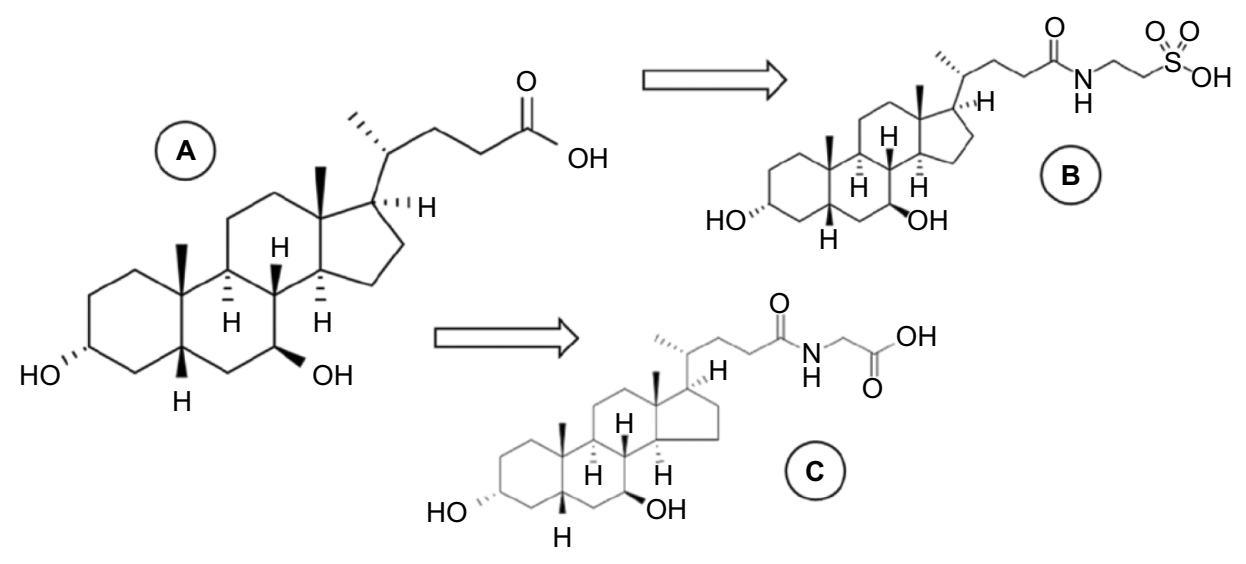

Figure I Chemical structure of UDCA (A) and its main metabolites, GUDCA (B) and TUDCA (C).

Abbreviations: GUDCA, glycoursodeoxycholic acid; TUDCA, tauroursodeoxycholic acid; UDCA, ursodeoxycholic acid. 
while their respective deuterated internal standards (ISs) were purchased from IsoSciences (Pennsylvania, Ambler, USA). Human plasma was obtained from UNIFAG (Bragança Paulista, SP, Brazil). The type I water HPLC grade was obtained internally using a Millipore Academic purification system. Acetonitrile and methanol $(\mathrm{MeOH})$ were purchased from J.T. Baker-Avantor (Xalostoc, Mexico), and ammonium acetate, hydrochloric acid $(\mathrm{HCl})$, diethyl ether, dichloromethane, ammonium hydroxide, and ethyl acetate were purchased from EMD Millipore (Billerica, MA, USA).

\section{Stock solutions and standards}

The stock solutions of analytes (UDCA, GUDCA, and TUDCA) and their respective deuterated IS were prepared by mixing appropriate amounts of the standards with $\mathrm{MeOH}$ to obtain solutions at the respective concentrations: $100.0 \mu \mathrm{g} /$ $\mathrm{mL}$ for TUDCA, TUDCA $\mathrm{D}_{4}$, and GUDCA $\mathrm{D}_{4} ; 200.0 \mu \mathrm{g} / \mathrm{mL}$ for UDCA $\mathrm{D}_{4}$, and $500.0 \mu \mathrm{g} / \mathrm{mL}$ for UDCA and GUDCA. The stock solutions were stored in a refrigerator with controlled temperature in a range of $2^{\circ} \mathrm{C}-8^{\circ} \mathrm{C} \pm 2^{\circ} \mathrm{C}$.

From these solutions, the respective working solutions were prepared and used to obtain the calibration curve composed of eight points in the range of $15-10,000 \mathrm{ng} / \mathrm{mL}$ for UDCA/GUDCA and $5-500 \mathrm{ng} / \mathrm{mL}$ for TUDCA. Spiking was performed on human plasma with an appropriate amount of each analyte. Quality controls (QCs) were spiked similarly to calibration curve points at the concentration of $45,5,000$, and $8,000 \mathrm{ng} / \mathrm{mL}$ for UDCA/GUDCA and 15, 250, and 400 $\mathrm{ng} / \mathrm{mL}$ for TUDCA.

\section{Sample preparation UDCA}

The UDCA samples were prepared by liquid-liquid extraction done by shaking $450 \mu \mathrm{L}$ of UDCA spiked plasma samples with $50 \mu \mathrm{L}$ of $9.0 \mu \mathrm{g} / \mathrm{mL} \mathrm{UDCA} \mathrm{D}_{4}$ solution prepared in $\mathrm{MeOH}, 50 \mu \mathrm{L}$ of $1 \mathrm{M} \mathrm{HCl}$ solution, and $1,250 \mu \mathrm{L}$ diethyl ether/dichloromethane $(70: 30 \mathrm{v} / \mathrm{v})$ for 5 minutes on a shaker table and then centrifuged for 10 minutes (relative centrifugal force [RCF]: $\left.18,506 \times g, 4^{\circ} \mathrm{C}\right) .850 \mu \mathrm{L}$ of the supernatant was transferred to another microtube and reserved. 1,250 $\mu \mathrm{L}$ of diethyl ether/dichloromethane $(70: 30 \mathrm{v} / \mathrm{v})$ was added to the remaining plasma; it was shaken for 5 minutes and then centrifuged for 10 minutes (RCF: $18,506 \times g, 4^{\circ} \mathrm{C}$ ). $850 \mu \mathrm{L}$ of supernatant was transferred to the reserved microtube and was dried under nitrogen flow and resuspended in $150 \mu \mathrm{L}$ of acetonitrile/ammonium acetate $10 \mathrm{mM} /$ ammonium hydroxide (70:30:0.1 v/v/v), was shaken for 2 minutes, and then $30 \mu \mathrm{L}$ was injected for analysis.

\section{GUDCA}

Like the UDCA samples, the GUDCA samples were prepared by liquid-liquid extraction, shaking $300 \mu \mathrm{L}$ of GUDCA spiked plasma with $50 \mu \mathrm{L}$ of $3.0 \mu \mathrm{g} / \mathrm{mL}$ glycosodeoxycholic $\mathrm{D}_{4}$ solution in $\mathrm{MeOH}$ and $50 \mu \mathrm{L}$ of $1 \mathrm{M} \mathrm{HCl}$ solution for 1 minute on a shaker table. Then, $1,250 \mu \mathrm{L}$ of diethyl ether/ dichloromethane $(70: 30 \mathrm{v} / \mathrm{v})$ was added, and the sample was shaken again for 5 minutes and then centrifuged for 10 minutes (RCF: $18,506 \times g, 4^{\circ} \mathrm{C}$ ). $900 \mu \mathrm{L}$ of the supernatant was transferred to another microtube. This was dried under nitrogen flow and resuspended in $150 \mu \mathrm{L}$ of acetonitrile/ ammonium acetate $10 \mathrm{mM} /$ ammonium hydroxide (70:30:0.1 $\mathrm{v} / \mathrm{v} / \mathrm{v}$ ), shaken for 2 minutes and then $15 \mu \mathrm{L}$ were inject for analysis.

\section{TUDCA}

TUDCA samples were prepared by deproteinization extraction (precipitation), shaking $400 \mu \mathrm{L}$ of TUDCA spiked plasma with $50 \mu \mathrm{L}$ of $2.0 \mu \mathrm{g} / \mathrm{mL}$ TUDCA $\mathrm{D}_{4}$ solution in acetonitrile $(\mathrm{MeCN})$ and $1,250 \mu \mathrm{L}$ of ethyl acetate for 3 minutes on a shaker table and then centrifuged for 5 minutes (RCF: $18,506 \times g, 4^{\circ} \mathrm{C}$ ). Samples were frozen for 10 minutes in a $-70^{\circ} \mathrm{C}$ freezer, the supernatant was discarded, and after complete thawing of the residual sample, $600 \mu \mathrm{L}$ of acetonitrile was added. The mixture was shaken for 5 minutes and centrifuged for 10 minutes (RCF: $18,506 \times g, 4^{\circ} \mathrm{C}$ ). $500 \mu \mathrm{L}$ of supernatant was transferred to another microtube, $150 \mu \mathrm{L}$ of Milli-Q ultrapure water was added and shaken for 2 minutes, and then $20 \mu \mathrm{L}$ was injected for analysis.

\section{Chromatography and quantification}

The chromatographic systems used were HPLC (Shimadzu, Japan) coupled to a Quattro Micro/Quattro Premier mass spectrometer (Waters, Milford, MA, USA) for each of the three analytes. The chromatographic separation was done through a Phenomenex Luna $5 \mu$ C18 100A $250 \times$ $4.6 \mathrm{~mm}$ (Torrence, USA) column for the three analytes, with a mobile phase consisting of acetonitrile/ammonium acetate $30 \mathrm{mM}(420: 580, \mathrm{v} / \mathrm{v}), \mathrm{pH} 7.0$, for the UDCA; acetonitrile/ammonium acetate $10 \mathrm{mM} /$ ammonium hydroxide (400:600:0.5, v/v/v), pH 9.0, for the GUDCA; and acetonitrile/ammonium acetate $10 \mathrm{mM}(570: 430, \mathrm{v} / \mathrm{v}), \mathrm{pH} 7.0$, for the TUDCA. The mobile phase flows were set at 0.450 $\mathrm{mL} / \mathrm{min}$ for UDCA (with gradient: $0.01-0.51$ minute, 0.45 $\mathrm{mL} / \mathrm{min}-50 \mathrm{kgf} ; 0.52-1.90$ minutes, $2.00 \mathrm{~mL} / \mathrm{min}-200$ Kgf; 1.91 minute, $0,45 \mathrm{~mL} / \mathrm{min}-50 \mathrm{kgf}$ ), $0.700 \mathrm{~mL} / \mathrm{min}$ for GUDCA (with gradient: $0.01-2.50$ minutes, $0.700 \mathrm{~mL} /$ min $-85 \mathrm{kgf} ; 2.51-4.75$ minutes, $0.35 \mathrm{~mL} / \mathrm{min}-44 \mathrm{kgf}$; 4.76 minute, $0.700 \mathrm{~mL} / \mathrm{min}-85 \mathrm{kgf}$ ), and $0.200 \mathrm{~mL} / \mathrm{min}$ 
for TUDCA (with gradient: 0.01-0.1 minute/1.21-5.5 minutes and 7.51 minutes, $0.200 \mathrm{~mL} / \mathrm{min}-20 \mathrm{kgf}$; $0.11-1.2$ minutes and 5.51-7.5 minutes, $1.5 \mathrm{~mL} / \mathrm{min}-130 \mathrm{kgf}$ ).

The use of a splitter was not necessary. Under the described conditions, the UDCA, GUDCA, and TUDCA elution times are of $3.47,3.34$, and 3.19 with a total run time of $6.50,5.00$, and 8.00 , respectively. Ions were monitored by an electrospray ion source (ESI) mass spectrometer, operating in a negative ionization mode, and the transitions measured were $\mathrm{m} / \mathrm{z} 391.30>\mathrm{m} / \mathrm{z} 373.41$ for UDCA, m/z $395.42>$ m/z 377.15 UDCA D, $\mathrm{m} / \mathrm{z} 448.46$ $>$ m/z 73.70 for GUDCA, m/z $451.92>\mathrm{m} / \mathrm{z} 73.70$ for GUDCA D $_{4}, \mathrm{~m} / \mathrm{z} 498.00>\mathrm{m} / \mathrm{z} 79.63$ for TUDCA, and m/z $502.44>\mathrm{m} / \mathrm{z} 79.54$ for TUDCA $\mathrm{D}_{4}$, as shown in Figures $2-7$. The quantification of analytes in human plasma was based on the peak area ratio of the analytes by the IS. The determination of the concentration of analytes in human plasma was determined from calibration curves that were

Ursodiol $5 \mathrm{ug} / \mathrm{mL}$ FM-FM MeCN/ $\mathrm{H}_{2} \mathrm{O} / \mathrm{NH}_{4} \mathrm{OH}$ 90/10/0.05

Desevolvimento 14-01-2016_265 (0.227) Cm (4.5)

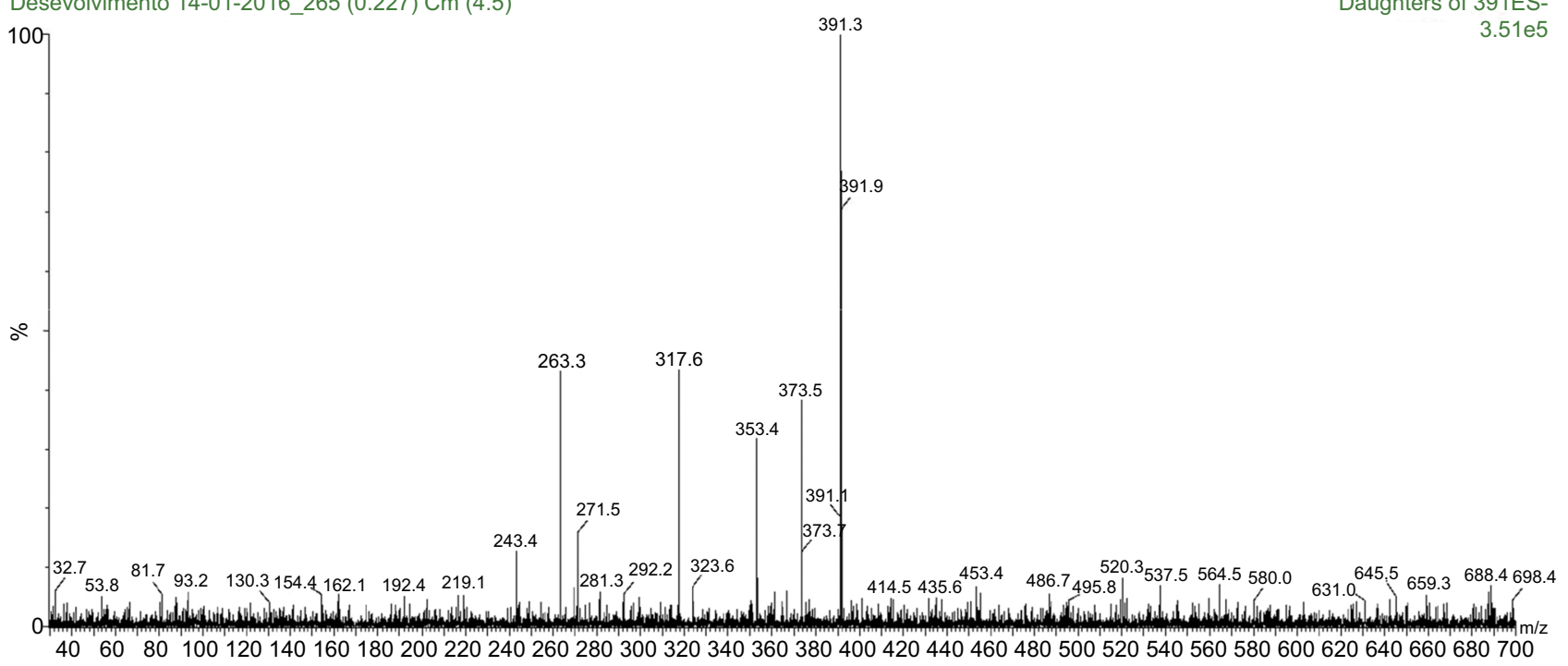

Figure 2 MS/MS spectrum of ursodeoxycholic acid: precursor ion m/z 391.3 Da product ion, used to form the monitoring channel, $\mathrm{m} / \mathrm{z} 373.5 \mathrm{Da}$.

Abbreviation: $M S / M S$, tandem mass spectrometry.

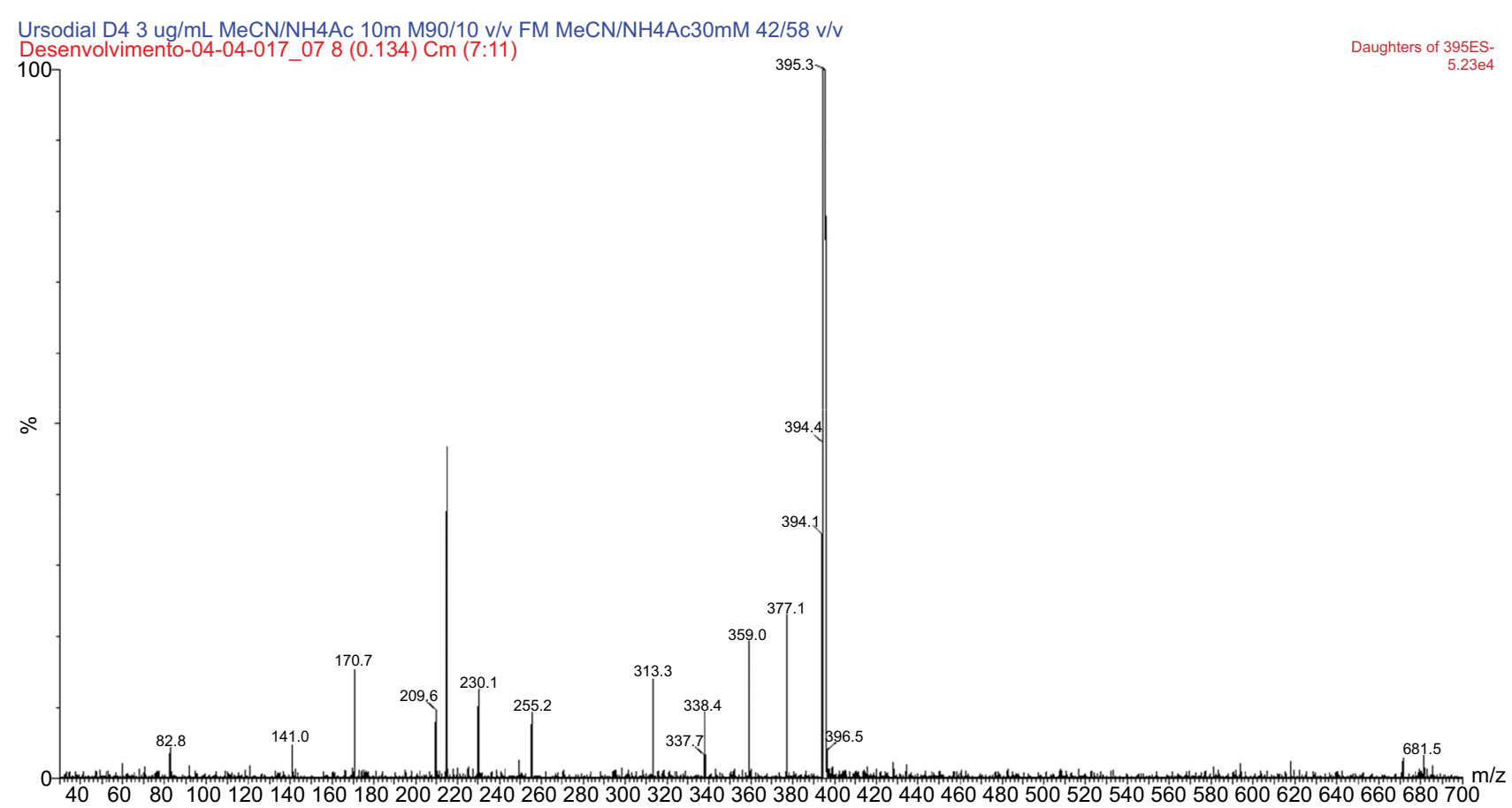

Figure $3 \mathrm{MS} / \mathrm{MS}$ spectrum of ursodeoxycholic acid $\mathrm{D}_{4}$ : precursor ion m/z 395.3 Da product ion, used to form the monitoring channel, $\mathrm{m} / \mathrm{z} 377 . \mathrm{I}$ Da. Abbreviation: MS/MS, tandem mass spectrometry. 
analyzed by linear regression using the least squares method (linear correlation coefficient $1 / \mathrm{x}^{2}$ ).

\section{Results and discussion Method development}

The chromatographic conditions were defined from several internal tests, seeking to obtain a higher peak response, with good resolution, symmetry, and the shortest running time, using the available materials.
The mobile phase for quantification of UDCA was defined after several tests, first acetonitrile/water/ammonium hydroxide (90:10:0.05-20:80:0.05 v/v/v) and acetonitrile/ water $(60: 40 \mathrm{v} / \mathrm{v})$, where the existence of a peak at the same retention time of analyte was observed after testing with blank plasma, which persisted even in the absence of organic modifiers. An increases in water $(80 \mathrm{~mL})$ resulted in a slight separation of these peaks when compared to blank samples and spiked samples. These results showed that the peak observed

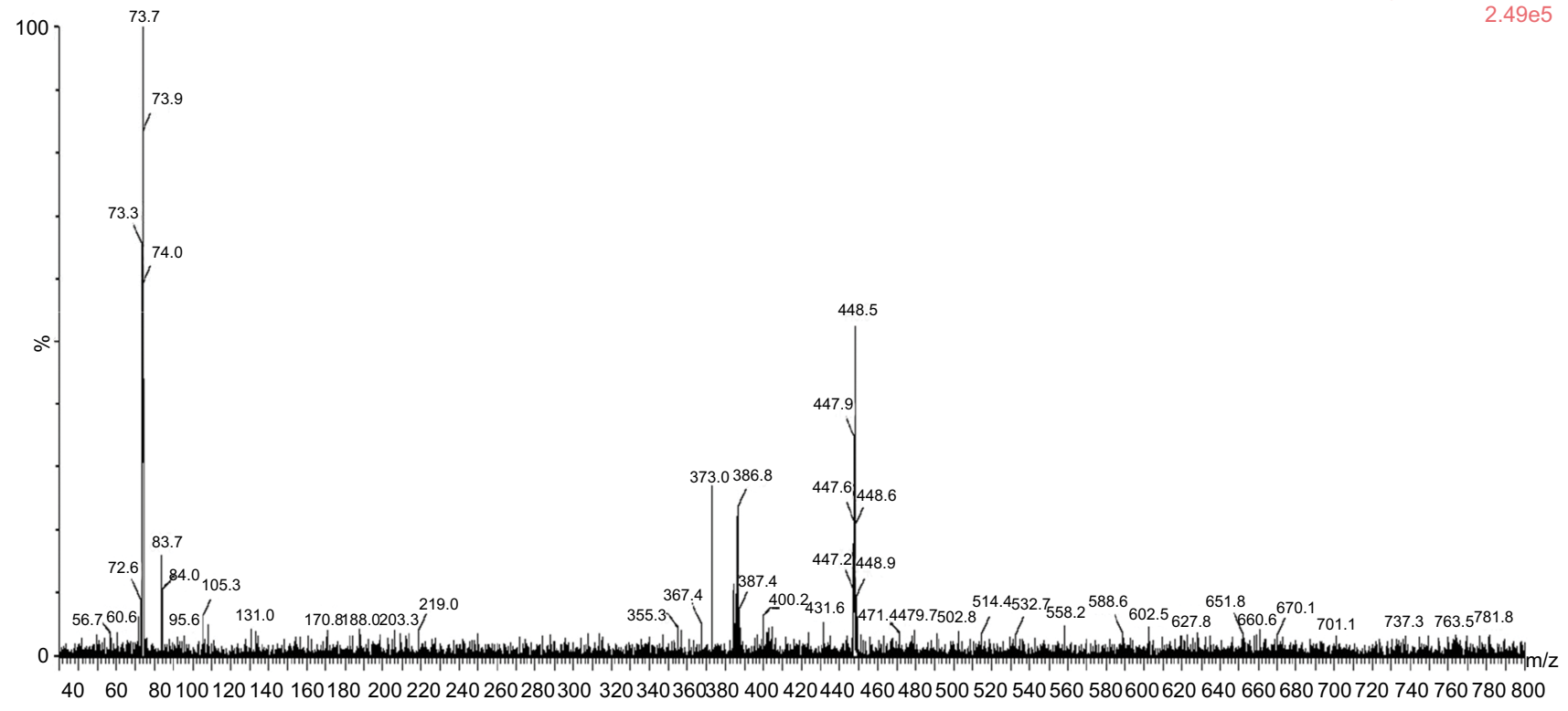

Figure $4 \mathrm{MS} / \mathrm{MS}$ spectrum of glycosodeoxycholic acid: precursor ion m/z $448.5 \mathrm{Da}$ product ion, used to form the monitoring channel, $\mathrm{m} / \mathrm{z} 73.7 \mathrm{Da}$. Abbreviation: MS/MS, tandem mass spectrometry.

\section{Glico 1 ug/mL FM FM MeCN/H2O 80/20 s col}

Desenvolvimento-19-04-17_1509 (0.196) Sm (Mn, 1x0.50), Cm (8:11)

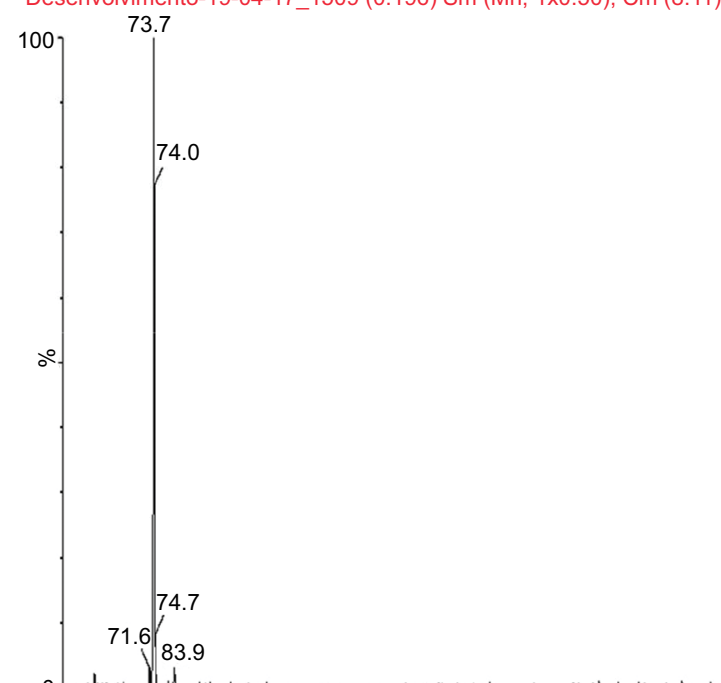

Daughters of $452 E S-$ $1.38 \mathrm{e} 6$

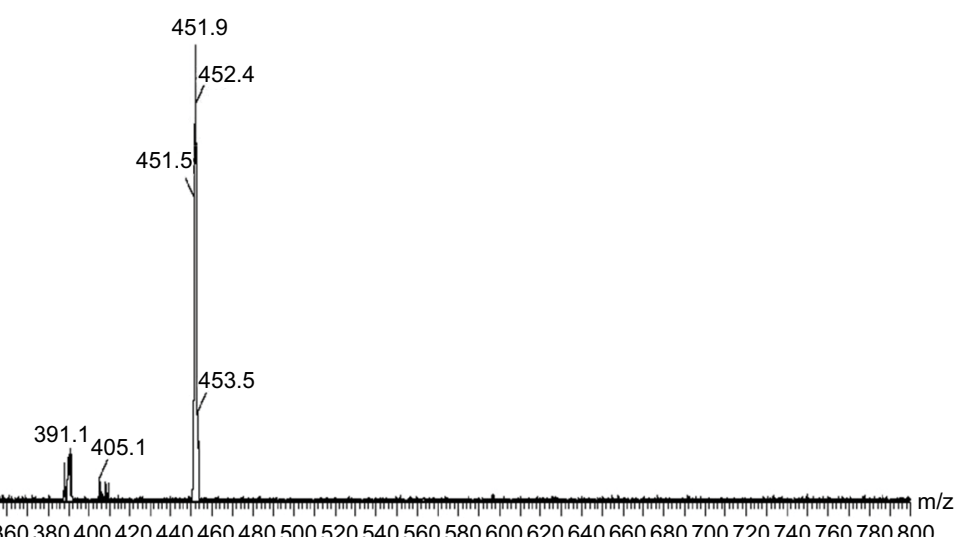

Figure 5 MS/MS spectrum of glycosodeoxycholic acid $D_{4}$ : precursor ion m/z 45I.9 Da product ion, used to form the monitoring channel, m/z $73.7 \mathrm{Da}$. Abbreviation: MS/MS, tandem mass spectrometry. 


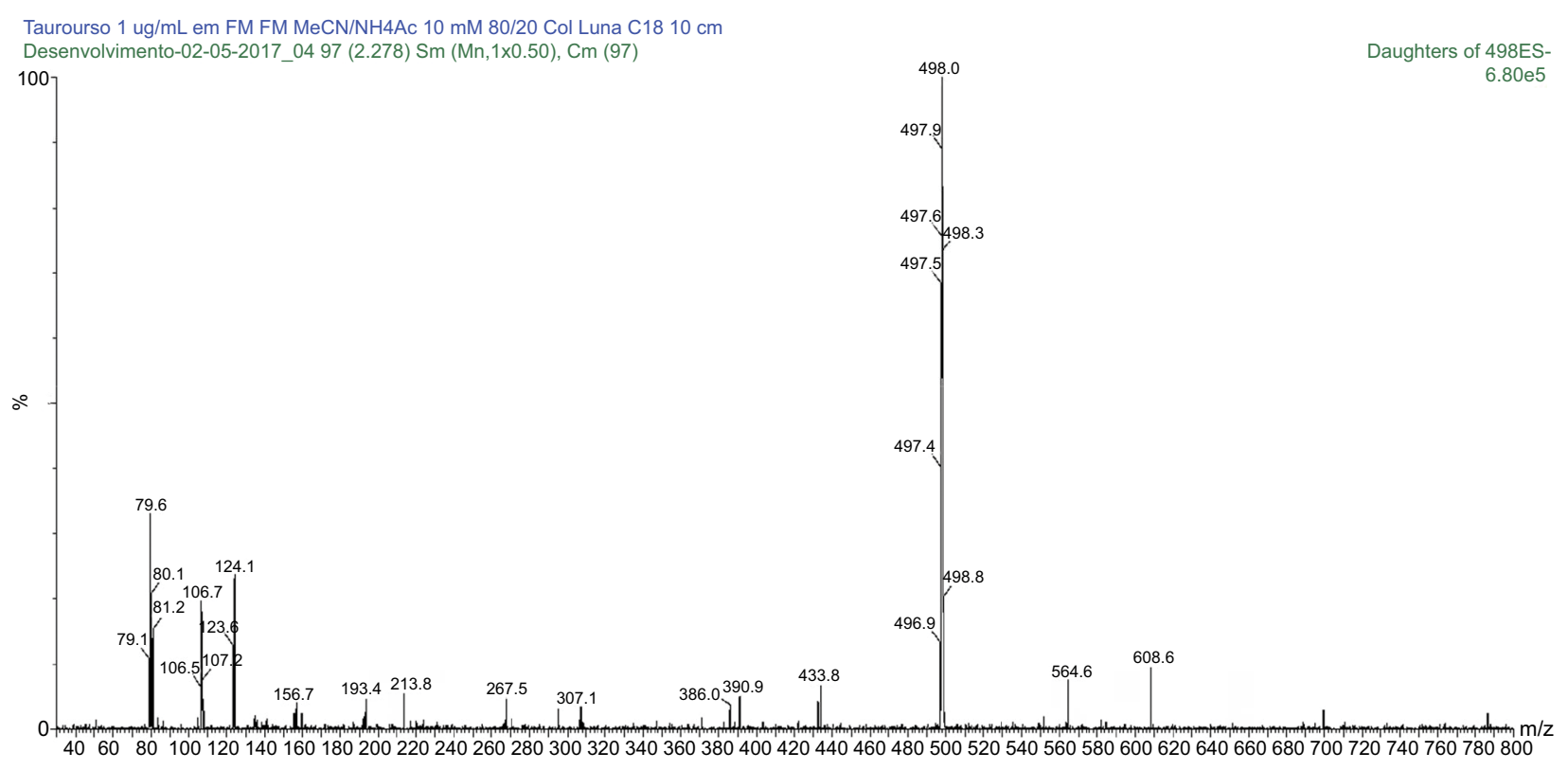

Figure $6 \mathrm{MS} / \mathrm{MS}$ spectrum of taurodeoxycholic acid: precursor ion m/z 498.0 Da product ion, used to form the monitoring channel, $\mathrm{m} / \mathrm{z} 79.6 \mathrm{Da}$. Abbreviation: MS/MS, tandem mass spectrometry.

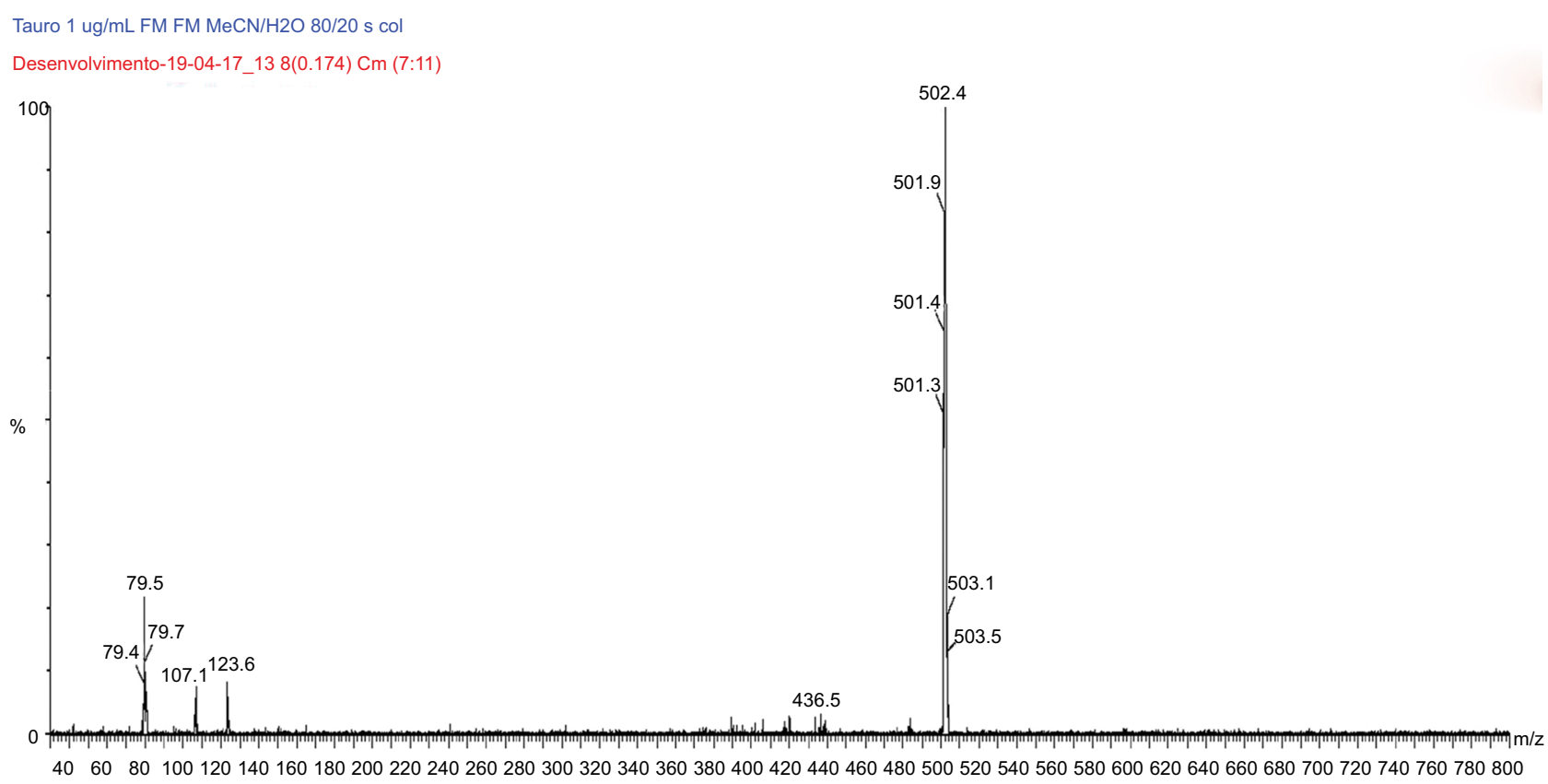

Figure $7 \mathrm{MS} / \mathrm{MS}$ spectrum of tauroursodeoxycholic acid $\mathrm{D}_{4}$ : precursor ion m/z 502.4 Da product ion, used to form the monitoring channel, $\mathrm{m} / \mathrm{z} 79.5 \mathrm{Da}$. Abbreviation: MS/MS, tandem mass spectrometry.

in plasma samples corresponded to an intense eluting with the active. Accordingly, mobile phase tests were performed in several volumes of acetonitrile/water, acetonitrile/ammonium acetate $10 \mathrm{mM} /$ ammonium hydroxide, acetonitrile/water/ ammonium hydroxide; acetonitrile/ammonium acetate 10 $\mathrm{mM}$; acetonitrile/ammonium acetate $20 \mathrm{mM}$; and acetonitrile/ammonium acetate $30 \mathrm{mM}$. The last solution presented an excellent separation and chromatographic resolution in the proportion of 42:58 $(\mathrm{v} / \mathrm{v})$, and so this was the mobile phase chosen for the method. In these tests, the addition of ammonium acetate to the mobile phase favored a decrease in retention time of the peaks, while also minimizing the chromatographic variation and separation between analytes and interferents. The ammonium hydroxide was added as an organic modifier with basic characteristics, but in spite of promoting a significant increase of the electronic signal, it caused a smaller separation and chromatographic resolution. The water increase leads to an electronic signal decrease, making it difficult to quantify the lower limit of quantification (LLOQ), and so it was withdrawn from the final solution. 
The mobile phase initially used to quantify the metabolites was acetonitrile/water/ammonium hydroxide (80:20:0.05 $\mathrm{v} / \mathrm{v} / \mathrm{v}$ ), which resulted in an electronic signal gain for the two substances. However, these tests revealed peak spreading at the area of interest, so new mobile phases were tested as follows: without ammonium hydroxide, with ammonium acetate in its place, and with the presence of both those modifiers. The mobile phase with $10 \mathrm{mM}$ ammonium acetate only presented the best result for precipitation tests, and so the mobile phase acetonitrile/ammonium acetate $10 \mathrm{mM}$ (57:43 $\mathrm{v} / \mathrm{v}$ ) was used for TUDCA. However, after accuracy tests for GUDCA, interference peaks were observed, and so the mobile phase was changed to acetonitrile/ammonium acetate $10 \mathrm{mM}(60: 40 \mathrm{v} / \mathrm{v})$, which leads to the separation of those peaks, but it was insufficient. Other proportions were tested: 80:20-50:50-40:60 v/v and the 40:60 v/v that presented the best results. Furthermore, organic modifiers were added to that mobile phase (ammonium hydroxide) in the hopes of improving the signal and chromatographic separation. The new mobile phase demonstrated effectiveness with a proportion of acetonitrile/ammonium acetate $10 \mathrm{mM} /$ ammonium hydroxide (40:60:0.5 v/v/v).

The following columns were also tested for UDCA determination: Synergi Fusion $25 \mathrm{~cm}$, Luna Phenyl Hexyl $25 \mathrm{~cm}$, Ace PFP C18 $15 \mathrm{~cm}$, and Luna $5 \mu \mathrm{C} 18100 \mathrm{~A} 25 \mathrm{~cm}$, the last one being the most efficient in separation of the interferer that eluted after the peak of interest. To stabilize possible variations in the column temperature that could affect its stability, an column oven was coupled keeping it at a temperature of $30^{\circ} \mathrm{C}$ and the dwell time parameter (speed scan) was increased to minimize the number of scans per seconds, thereby decreasing variations in retention time. For TUDCA and GUDCA, Luna $5 \mu \mathrm{m}$ C18 100×4.6 mm, Phenomenex C18 $100 \times 4.6 \mathrm{~mm}$, Phenomenex $15 \mathrm{~cm} \mathrm{C18}$, Phenyl-Hexyl $15 \mathrm{~cm}$, and Luna Phenomenex $5 \mu \mathrm{C} 18$ 100A $25 \mathrm{~cm}$ columns were tested. The last one presented the best results in the separation of interfering peaks that had been found for GUDCA, also in obtaining a satisfactory result for TUDCA.

The UDCA resuspension solution was obtained from several tests to improve the electronic signal. Several proportions of acetonitrile/water/formic acid; acetonitrile/water; acetonitrile/water/ammonium hydroxide; acetonitrile/ammonium acetate $10 \mathrm{mM}$; and acetonitrile/water/ammonium hydroxide were tested. Although the last option presented a good electronic signal $(90: 10: 0.05 \mathrm{v} / \mathrm{v} / \mathrm{v})$, the exclusion of base from the resuspension solution was important for the stabilization of retention time; thus, the solution chosen was acetonitrile/ ammonium acetate $10 \mathrm{mM}(90 / 10 \mathrm{v} / \mathrm{v})$. The use of $1 \mathrm{M} \mathrm{HCl}$ in extractions of GUDCA showed better recovery results. In addition, several tests were performed for resuspension solution of this metabolite: acetonitrile/ammonium acetate $10 \mathrm{mM} /$ ammonium hydroxide in 40:60:0.5, 80:20:01, and $70: 30: 0.1 \mathrm{v} / \mathrm{v} / \mathrm{v}$ proportions, and the last option was chosen since it assisted in the elimination of peak spreading problems.

During extraction tests, the liquid-liquid technique was used because it is the most suitable method for predominantly nonpolar compounds, such as UDCA and GUDCA, especially because in its extraction process was made use of solvents and reagents with this characteristic. For TUDCA, the deproteinization technique was used due to its polar nature. The solid phase method, albeit cleaner and more effective, was not chosen due to its high cost, which made it infeasible for the purpose of this study.

For UDCA analysis, a flow of $0.450 \mathrm{~mL} / \mathrm{min}$ was defined based on the gradient tests, which led to a considerable reduction in the time for each analysis. The channels defined were MRM m/z $391.30>$ m/z 373.5 for UDCA and MRM channel $\mathrm{m} / \mathrm{z} 395.3>\mathrm{m} / \mathrm{z} 377.1$ for UDCA $\mathrm{D}_{4}$ operating on ESI in a negative ionization mode (ESI-). The $\mathrm{m} / \mathrm{z}$ 391.20> $\mathrm{m} / \mathrm{z} 355.04$ channel was also tested for the analyte, but showed chromatographic interferences and poor solubility. For metabolites, signals of their respective masses were only observed in a negative ionization mode (ESI-), using a flow of $0.700 \mathrm{~mL} / \mathrm{min}$ for GUDCA and $0.200 \mathrm{~mL} / \mathrm{min}$ for TUDCA, and a gradient was also necessary. The channels were defined as specified earlier.

Thus, a test of accuracy and precision was carried out to confirm the efficiency and effectiveness of the method. With the chosen technique, a triplicate curve was obtained, nine QCs of each concentration and nine LLOQs (lower limit of quantification) for each compound separately (UDCA, GUDCA, and TUDCA). The test was injected and reinjected. There was no change in the analytes' retention times.

\section{Validation of the analytical methodology Selectivity}

Selectivity is the ability of a method to differentiate and quantify the analyte and IS in the presence of other components of the sample. In this test, it is necessary to compare the biological matrix, obtained from different sources, to investigate interferents that may affect the selectivity of method. Thus, lipemic samples (with high lipid content) and hemolysate (containing lysed erythrocytes) must also be tested. ${ }^{15-17}$ To confirm the selectivity of the method, blank samples of 
human plasma obtained from six different individuals were analyzed, with four normal samples, one lipemic sample, and one hemolysed sample for each analyte.

The samples were tested using the extraction procedure and the chromatographic conditions developed to evaluate possible interferences in retention time of the drug and IS. The results were compared with those obtained with processed samples of LLOQ from each analyte (Figures 8-10).

The interfering peak responses near the retention time of the analyte should be less than $20 \%$ of the analyte response in the LLOQ samples and less than $5 \%$ of the IS response. As a result, there were no significant interfering responses at the retention times of analytes and IS, demonstrating the selectivity of the method in a biological matrix composed of human plasma.

\section{Residual effect (carryover)}

The residual effect, or carryover, is the effect generated by the appearance of or increase in the analyte or IS signal from contamination of previous samples. For that to be tested, it is necessary to consecutively inject a blank sample, a sample containing the analyte in the upper limit of quantification (ULOQ) concentration with IS, and then two blank samples. ${ }^{14}$ To evaluate whether there was any carryover effect, three injections of the same white sample were analyzed, with one made before and two soon after injection of the ULOQ sample.

Results were compared with those obtained in the LLOQ processed sample for each analyte.

The interfering peak responses near the retention time of the analyte should be less than $20 \%$ of the analyte response in the LLOQ samples and less than $5 \%$ of the IS response.

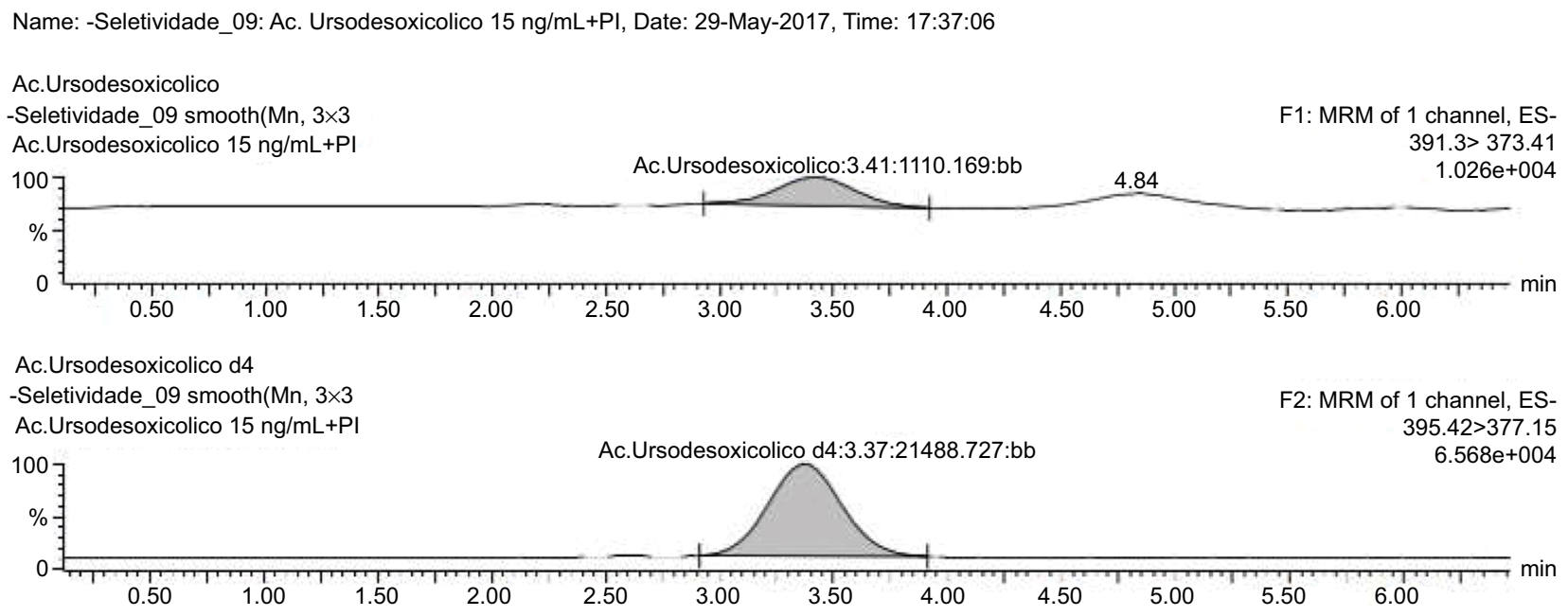

Figure 8 Normal blank plasma PLS 76/20I7 related to analyte and internal standard.

Name: -Seletividade_09: Ac. Glicoursodesoxicolico 15 ng/mL+PI, Date: 26-May-2017, Time: 16:16:35

Ac.Glicoursodesoxicolico

-Seletividade_09 smooth(Mn, 3×3

Ac.Glicoursodesoxicolico $15 \mathrm{ng} / \mathrm{mL}+\mathrm{PI}$

1007

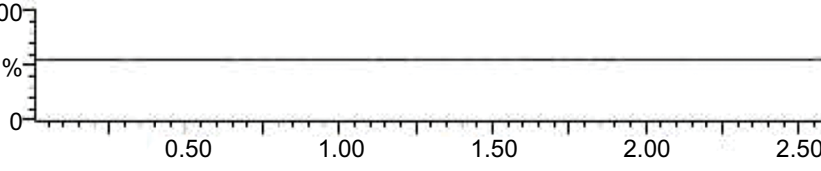

Ac.Glicoursodesoxicolico:3.34:1206.602:bb

F1: MRM of 1 channel, ES-

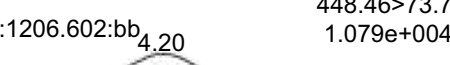

Ac.Glicoursodesoxicolico D4

-Seletividade_09 smooth $(\mathrm{Mn}, 3 \times 3$

Ac. Glicoursodesoxicolico $15 \mathrm{ng} / \mathrm{mL}+\mathrm{PI}$

100
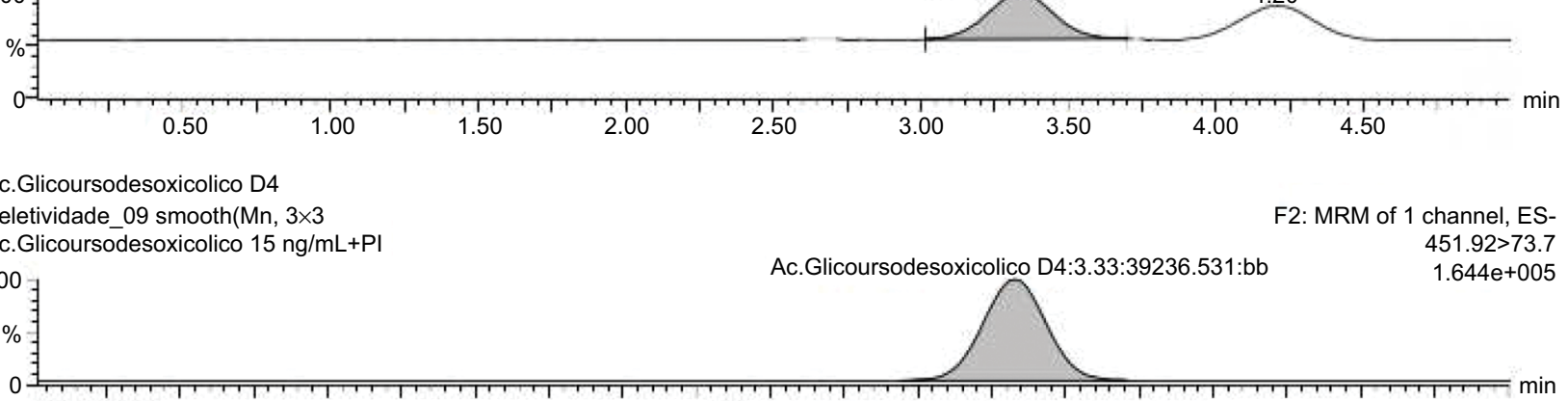

gure 9 Normal blank plasma PLS 65/20I7 related to analyte and internal standard. 
As a result, there were no interfering responses at the retention time of the analytes and IS, ie, no residual effect was observed in the methods developed.

\section{Matrix effect}

Substances coeluted with the analyte, but undetected, may reduce or increase the signal intensity corresponding to the mass transition of that analyte, affecting precision, accuracy, robustness, selectivity, and sensitivity of the method. This is a phenomenon called matrix effect, and its determination in the development and validation stages is fundamental to ensure the reliability and selectivity of the method. ${ }^{18-21}$ Therefore, to evaluate whether there was a matrix effect, samples from eight different sources were analyzed (four normal, two lipemic, and two hemolysates), and analyte and IS were spiked at the same concentrations of lower and higher QC. The results were evaluated from the normalized matrix factor (NMF) calculation for the three analytes, respectively. The result showed that there was no significant interference of the plasma matrix.

\section{Lower limit of quantification, linearity, precision, and accuracy}

The established LLOQ was $15 \mathrm{ng} / \mathrm{mL}$ for UDCA and GUDCA and $5 \mathrm{ng} / \mathrm{mL}$ for TUDCA. A linear response for the peak area ratio (response) vs concentration in a range of 15-10,000 ng/mL for UDCA/GUDCA and 5-500 $\mathrm{ng} / \mathrm{mL}$ for TUDCA (Tables $1-3$, respectively), with a mean linear correlation coefficient of $0.9985(n=8)$ or better must be evaluate. Intralot accuracy and precision were determined by the analysis of nine replicates of LLOQ, lower CQ, medium QC, higher QC, and a diluted QC in five levels of concentration extracted on the same day, while the inter-lot evaluation was determined by the analysis of three calibration curves with each one of those nine controls with at least two being

Name: -Seletividade_09, Description: Ac. Taurosodesoxicolico 5 ng/mL+PI, Date: 12-Jun-2017, Time: 14:33:17

Ac. Taurosodesoxicolico

-Seletividade_09 smooth $(\mathrm{Mn}, 3 \times 3)$

Ac. Taurosodesoxicolico $5 \mathrm{ng} / \mathrm{mL}+\mathrm{PI}$

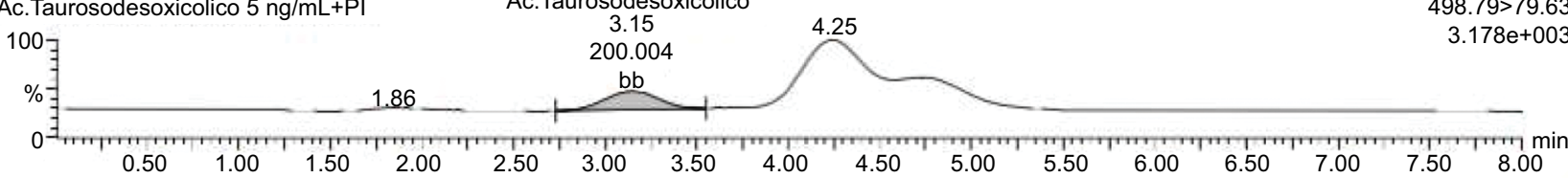

Ac. Taurosodesoxicolico D4

-Seletividade_09 smooth(Mn, 3×3)

Ac. Taurosodesoxicolico $5 \mathrm{ng} / \mathrm{mL}+\mathrm{PI}$

100 Э

$\%$

Ac. Taurosodesoxicolico D4:3.14:7310.761:bb

F2: MRM of 1 channel, ES $502.44>79.54$

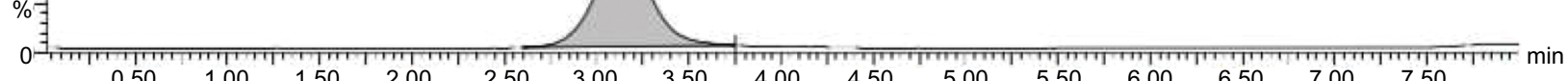

Figure 10 Normal blank plasma PLS 388/2016 related to analyte and internal standard.

Table I Ursodeoxycholic acid calibration curve data

\begin{tabular}{|c|c|c|c|c|c|c|}
\hline \multirow{2}{*}{$\begin{array}{l}\text { Nominal } \\
\text { concentration } \\
\text { (ng/mL) }\end{array}$} & \multicolumn{2}{|l|}{ Lot I } & \multicolumn{2}{|l|}{ Lot 2} & \multicolumn{2}{|l|}{ Lot 3} \\
\hline & $\begin{array}{l}\text { Experimental } \\
\text { concentration } \\
\text { (ng/mL) }\end{array}$ & $\begin{array}{l}\text { Deviation } \\
\text { (\%) }\end{array}$ & $\begin{array}{l}\text { Experimental } \\
\text { concentration } \\
(\mathrm{ng} / \mathrm{mL})\end{array}$ & $\begin{array}{l}\text { Deviation } \\
\text { (\%) }\end{array}$ & $\begin{array}{l}\text { Experimental } \\
\text { concentration } \\
\text { (ng/mL) }\end{array}$ & $\begin{array}{l}\text { Deviation } \\
\text { (\%) }\end{array}$ \\
\hline 15 & 14,446 & -3.69 & 14,635 & -2.44 & 15,282 & 1.88 \\
\hline 50 & 55,624 & 11.25 & 54,570 & 9.14 & 37,511 & $-24.98^{a}$ \\
\hline 100 & 102,702 & 2.70 & 97,945 & -2.05 & 86,926 & -13.07 \\
\hline $\mathrm{I}, 000$ & 957,397 & -4.26 & $1,018,494$ & 1.85 & $1,009,823$ & 0.98 \\
\hline 2,000 & $1,967,726$ & -1.61 & $1,966,279$ & -1.69 & $2,139,443$ & 6.97 \\
\hline 4,000 & $3,991,371$ & -0.22 & $3,893,776$ & -2.66 & $4,109,517$ & 2.74 \\
\hline 6,000 & $5,79 \mid, 528$ & -3.7 & $5,968,888$ & -0.52 & $6,120,767$ & 2.01 \\
\hline 10,000 & $9,930,706$ & -0.69 & $9,836,070$ & -1.64 & $9,848,776$ & -1.1 \\
\hline Equation & \multicolumn{2}{|c|}{$y=0.00139156 x+0.0191452$} & \multicolumn{2}{|c|}{$y=0.00134053 x+0.0230972$} & \multicolumn{2}{|c|}{$y=0.00130278 x+0.0385574$} \\
\hline
\end{tabular}

Note: a Deviations above the allowed limit of $15 \%$, this value was not included in the calculation of the curve equation. 
Table 2 Glycoursodeoxycholic acid calibration curve data

\begin{tabular}{|c|c|c|c|c|c|c|}
\hline \multirow{2}{*}{$\begin{array}{l}\text { Nominal } \\
\text { concentration } \\
(\mathbf{n g} / \mathrm{mL})\end{array}$} & \multicolumn{2}{|l|}{ Lot I } & \multicolumn{2}{|l|}{ Lot 2} & \multicolumn{2}{|l|}{ Lot 3} \\
\hline & $\begin{array}{l}\text { Experimental } \\
\text { concentration } \\
(\mathrm{ng} / \mathrm{mL})\end{array}$ & Deviation (\%) & $\begin{array}{l}\text { Experimental } \\
\text { concentration } \\
(\mathrm{ng} / \mathrm{mL})\end{array}$ & $\begin{array}{l}\text { Deviation } \\
\text { (\%) }\end{array}$ & $\begin{array}{l}\text { Experimental } \\
\text { concentration (ng/ } \\
\mathrm{mL})\end{array}$ & $\begin{array}{l}\text { Deviation } \\
\text { (\%) }\end{array}$ \\
\hline 15 & 14,906 & -0.63 & 14,932 & -0.45 & $|5| 3 \mid$, & 0.87 \\
\hline 50 & 50,538 & 1.08 & 50,543 & 1.09 & 48,650 & -2.70 \\
\hline 100 & 102,042 & 2.04 & 100,792 & 0.79 & 99,197 & -0.80 \\
\hline 1,000 & 991,528 & -0.85 & $1,010,979$ & 1.10 & $1,036,006$ & 3.60 \\
\hline 2,000 & $2,037,794$ & 1.89 & $1,988,106$ & -0.59 & $2,0|7,09|$ & 0.85 \\
\hline 4,000 & $4,036,213$ & 0.91 & $3,938,251$ & -1.54 & $4,044,8 \mid 4$ & 1.12 \\
\hline 6,000 & $5,974,005$ & -0.43 & $6,082,838$ & 1.38 & $5,968,408$ & -0.53 \\
\hline 10,000 & $9,599,408$ & -4.01 & $9,823,318$ & -1.77 & $9,758,223$ & -2.42 \\
\hline Equation & \multicolumn{2}{|c|}{$y=0.0019909 x+0.00610845$} & \multicolumn{2}{|c|}{$y=0.00199617 x+0.00795389$} & \multicolumn{2}{|c|}{$y=0.00196984 x+0.00750074$} \\
\hline
\end{tabular}

Table 3 Tauroursodeoxycholic acid calibration curve data

\begin{tabular}{|c|c|c|c|c|c|c|}
\hline \multirow{2}{*}{$\begin{array}{l}\text { Nominal } \\
\text { concentration } \\
(\mathbf{n g} / \mathbf{m L})\end{array}$} & \multicolumn{2}{|l|}{ Lot I } & \multicolumn{2}{|l|}{ Lot 2} & \multicolumn{2}{|l|}{ Lot 3} \\
\hline & $\begin{array}{l}\text { Experimental } \\
\text { concentration } \\
(\mathrm{ng} / \mathrm{mL})\end{array}$ & $\begin{array}{l}\text { Deviation } \\
\text { (\%) }\end{array}$ & $\begin{array}{l}\text { Experimental } \\
\text { concentration } \\
(\mathrm{ng} / \mathrm{mL})\end{array}$ & $\begin{array}{l}\text { Deviation } \\
\text { (\%) }\end{array}$ & $\begin{array}{l}\text { Experimental } \\
\text { concentration } \\
(\mathrm{ng} / \mathrm{mL})\end{array}$ & Deviation (\%) \\
\hline 5 & 4,932 & -1.37 & 4,871 & -2.58 & 5,162 & 3.24 \\
\hline 10 & 9,956 & -0.44 & 10,692 & 6.92 & 9,750 & -2.50 \\
\hline 20 & 21,486 & 7.43 & 19,238 & -3.81 & 18,245 & -8.77 \\
\hline 50 & 52,590 & 5.18 & 53,262 & 6.52 & 51,009 & 2.02 \\
\hline 100 & 85,046 & -14.95 & 88,543 & -11.46 & $81,92 I$ & $-18.08^{a}$ \\
\hline 200 & 184,987 & -7.51 & 186,820 & -6.59 & 184,426 & -7.79 \\
\hline 300 & $313,98 \mid$ & 4.66 & 321,609 & 7.20 & 324,854 & 8.28 \\
\hline 500 & 534,977 & 7.00 & 518,950 & 3.79 & 527,573 & 5.51 \\
\hline Equation & \multicolumn{2}{|c|}{$y=0,00403375 x+0,0125843$} & \multicolumn{2}{|c|}{$y=0,004|2367 x+0,0| 2335 \mid$} & \multicolumn{2}{|c|}{$y=0,0042758 \mid x+0,010892$} \\
\hline
\end{tabular}

Note: a Deviations above the allowed limit of $15 \%$, this value was not included in the calculation of the curve equation.

Table 4 Intraassay and interassay analyses of UDCA

\begin{tabular}{|c|c|c|c|c|c|c|c|c|c|c|}
\hline \multicolumn{11}{|c|}{ Intraassay precision and accuracy } \\
\hline \multirow[b]{2}{*}{ Replicates $(n=9)$} & \multicolumn{3}{|l|}{ LQC } & \multirow{2}{*}{$\begin{array}{l}\text { MQC } \\
\text { Lot I }\end{array}$} & \multirow[b]{2}{*}{ Lot 2} & \multirow[b]{2}{*}{ Lot 3} & \multicolumn{2}{|l|}{ HQC } & \multirow[b]{2}{*}{ Lot 2} & \multirow[b]{2}{*}{ Lot 3} \\
\hline & Lot I & Lot 2 & Lot 3 & & & & \multicolumn{2}{|l|}{ Lot I } & & \\
\hline Mean & 43,134 & 47,043 & 44,674 & $4,969,57 \mid$ & $4,988,898$ & $5,025,576$ & \multicolumn{2}{|l|}{$7,841,509$} & $8,020,286$ & $8,046,401$ \\
\hline SD & 4,355 & 3,291 & 6,381 & 99,720 & 95,988 & 96,083 & \multicolumn{2}{|l|}{101,452} & 125,976 & 136,082 \\
\hline CV (\%) & 10,097 & 6,995 & 14,283 & 2,007 & 1,924 & 1,912 & \multicolumn{2}{|l|}{1,294} & $I, 57 \mid$ & 1,691 \\
\hline RSE (\%) & $-4,147$ & 4,539 & $-0,723$ & $-0,609$ & $-0,222$ & 0,512 & \multirow[t]{2}{*}{$-1,98 \mid$} & & 0,254 & 0,580 \\
\hline Replicates (n=9) & \multicolumn{4}{|c|}{ DQC (lot I) } & \multicolumn{2}{|c|}{ DQC (lot 2) } & & \multicolumn{3}{|c|}{ DQC (lot 3) } \\
\hline Mean & \multicolumn{4}{|c|}{$4,350,024$} & 4,300 & 0,213 & & 4,339 & 9,477 & \\
\hline SD & 95,800 & & & & 80,39 & & & 90,44 & & \\
\hline CV (\%) & 2,202 & & & & 1,869 & & & 2,084 & & \\
\hline RSE (\%) & 2,354 & & & & 1,181 & & & 2,105 & & \\
\hline Replicates (n=9) & LLOQ & & & & LLO & $Q(\operatorname{lot} 2)$ & & LLO & $Q(\operatorname{lot} 3)$ & \\
\hline Mean & 14,550 & & & & 17,82 & & & 14,77 & & \\
\hline SD & $\mathrm{I}, 737$ & & & & 3,514 & & & 2,199 & & \\
\hline CV (\%) & 11,938 & & & & $|9,7|$ & & & 14,88 & & \\
\hline RSE (\%) & $-3,002$ & & & & 18,82 & & & $-|, 5|$ & & \\
\hline Interassay precisio & and acc & & & & & & & & & \\
\hline Replicates $(n=27)$ & LQC & & & & & HQC & DQ & & LL & \\
\hline Mean & 44,950 & & & 682 & & $7,969,399$ & 4,32 & 9,905 & 15, & \\
\hline SD & 4,938 & & & & & 149,527 & 88,3 & & 2,9 & \\
\hline CV (\%) & 10,984 & & & & & 1,876 & 2,04 & & 18 & \\
\hline RSE (\%) & $-0,110$ & & & & & $-0,383$ & $\mathrm{I}, 88$ & & 4,7 & \\
\hline
\end{tabular}

Note: Nominal concentration: $\mathrm{LQC}=45 \mathrm{ng} / \mathrm{mL}, \mathrm{MQC}=5,000 \mathrm{ng} / \mathrm{mL}, \mathrm{HQC}=8,000 \mathrm{ng} / \mathrm{mL}, \mathrm{DQC}=4,250 \mathrm{ng} / \mathrm{mL}(\mathrm{I}: 3), \mathrm{LLOQ}=15 \mathrm{ng} / \mathrm{mL}$.

Abbreviations: CV, coefficient of variation; LLOQ, lower limit of quantification; RSE, relative standard error; UDCA, ursodeoxycholic acid; LQC, lower quality control; MQC, medium quality control; HQC, high quality control; DQC, dilution quality control; LLOQ, lower limit of quantification. 
Table 5 Intraassay and interassay analyses of GUDCA

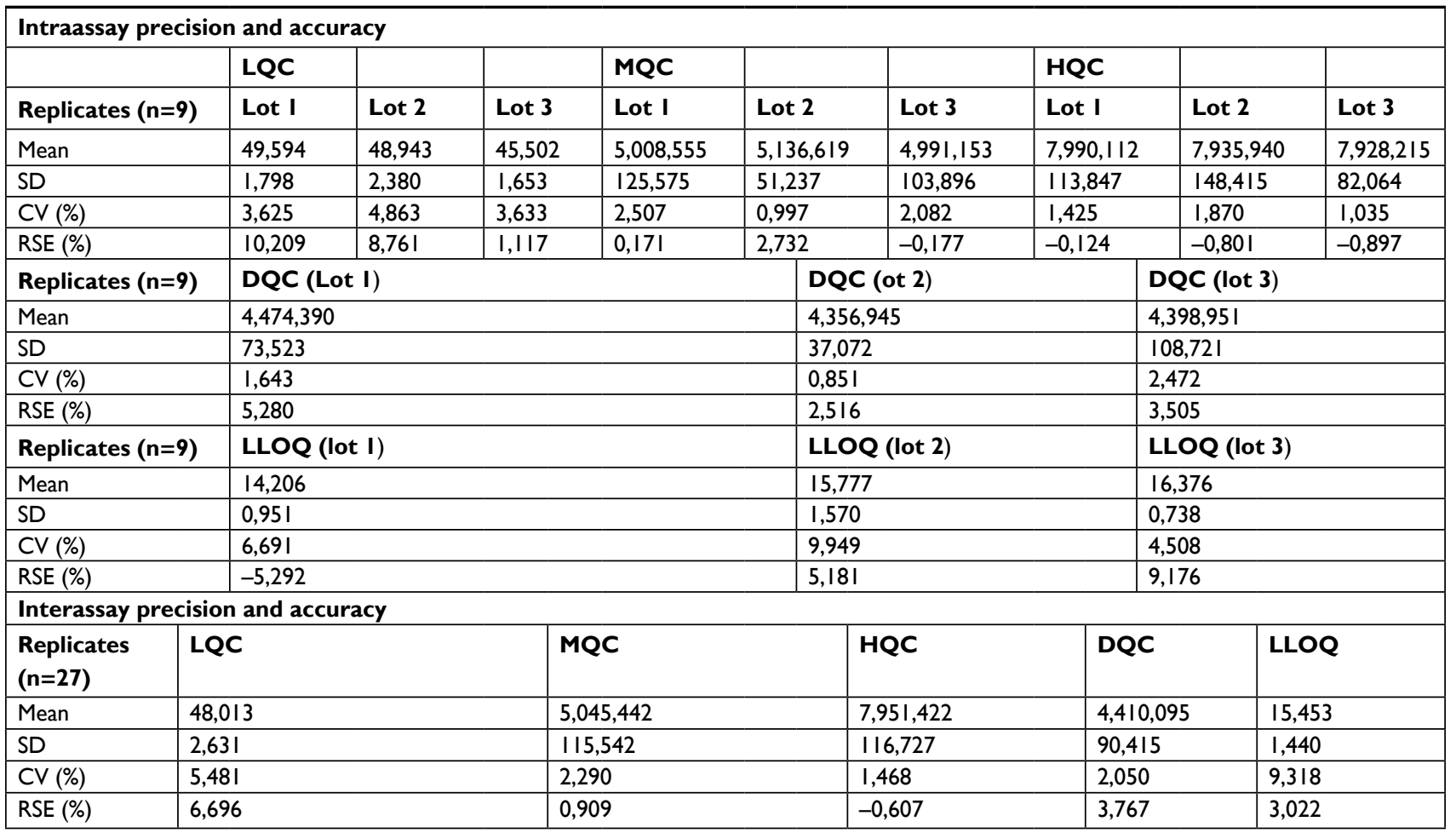

Note: Nominal concentration: LQC= $15 \mathrm{ng} / \mathrm{mL}, \mathrm{MQC}=250 \mathrm{ng} / \mathrm{mL}, \mathrm{HQC}=400 \mathrm{ng} / \mathrm{mL}, \mathrm{DQC}=2 / 2,5 \mathrm{ng} / \mathrm{mL}(\mathrm{l}: 3), \mathrm{LLOQ}=5 \mathrm{ng} / \mathrm{mL}$.

Abbreviations: CV, coefficient of variation; GUDCA, glycoursodeoxycholic acid; LLOQ, lower limit of quantification; RSE, relative standard error; LQC, lower quality control; MQC, medium quality control; HQC, high quality control; DQC, dilution quality control.

Table 6 Intraassay and interassay analyses of TUDCA

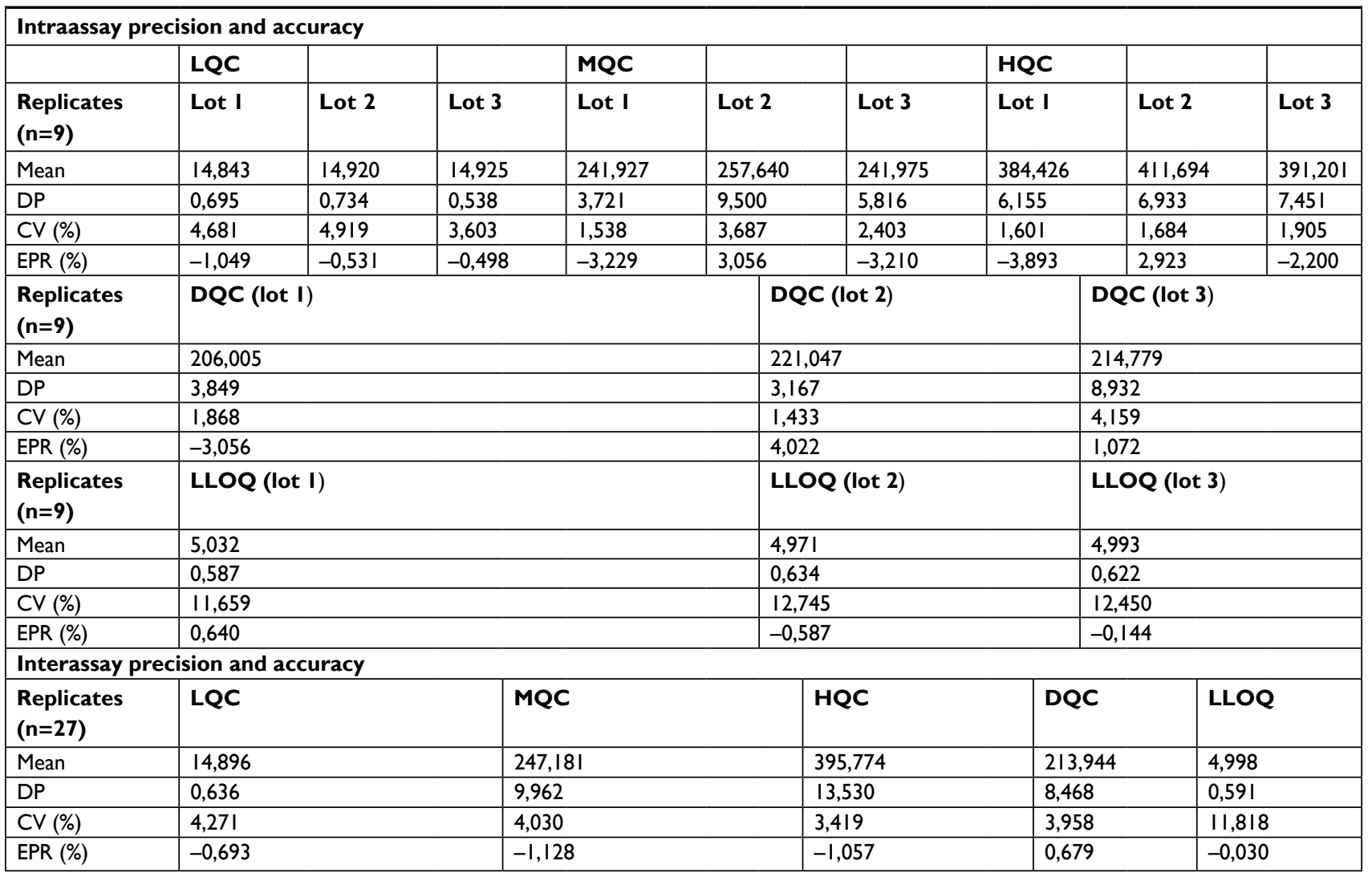

Note: Nominal concentration: $\mathrm{LQC}=45 \mathrm{ng} / \mathrm{mL}, \mathrm{MQC}=5,000 \mathrm{ng} / \mathrm{mL}, \mathrm{HQC}=8,000 \mathrm{ng} / \mathrm{mL}, \mathrm{DQC}=4,250 \mathrm{ng} / \mathrm{mL}(\mathrm{l}: 3), \mathrm{LLOQ}=15 \mathrm{ng} / \mathrm{mL}$.

Abbreviations: CV, coefficient of variation; LLOQ, lower limit of quantification; RSE, relative standard error; TUDCA, tauroursodeoxycholic acid; LQC, lower quality control; MQC, medium quality control; HQC, high quality control; DQC, dilution quality control. 
on different days. The details of the results obtained in those tests are presented in Tables 4-6.

The samples considered as reinjected were those that were quantified more than once. The validation of reinjection aims to evaluate the validity of this procedure, when necessary.

The validation of the reinjection for each analyte was demonstrated through the results obtained during the precision and accuracy test, where the mean values for each QC (lower quality control [LQC], medium quality control [MQC], and high quality control [HQC]) of the reinjection were evaluated in relation to the means obtained for the samples of the first injection. No deviation above $15 \%$ was observed among them.

\section{Stability}

The stability of the UDCA, GUDCA, and TUDCA plasma samples was determined in the conditions of use and storage: top-bench, autosampler, freeze-thaw, and long term. The solutions used were also evaluated in the top-bench conditions (room temperature) and in refrigerator conditions. Initially, a calibration curve and samples at lower QC and higher QC concentrations were spiked, extracted, quantified, freshly prepared, and evaluated according to the acceptance criteria of $15 \%$ in comparison to the nominal value of each concentration (this criterion was applied to other stabilities, except for solution). After acceptance, the samples are suitable for determining other stabilities. Thus, a fraction of those spiked plasma QCs used in the initial assay was kept on the bench at controlled room temperature $\left(18^{\circ} \mathrm{C}-24^{\circ} \mathrm{C}\right)$ for a period of 20 hours and 50 minutes for UDCA, 20 hours and 15 minutes for GUDCA, and 23 hours and 20 minutes for TUDCA. All of them remained stable during the period according to the previously established criterion. The processed samples were kept at autosampler (approximately $22^{\circ} \mathrm{C}$ ), and each QC sample was analyzed in six replicates initially (at zero time) and after 24 hours for the three analytes. The results showed that they remained stable during that period. The spiked samples were also used for the freezing and thawing process in three cycles for each analyte at $-20^{\circ} \mathrm{C}$. After comparing the results, it was observed that they remained stable after the process.

The long-term stability of the stored $\left(-20^{\circ} \mathrm{C}\right)$ spiked human plasma samples was evaluated for each analyte after 133 days (UDCA), 154 days (GUDCA), and 119 days (TUDCA). Comparing the variations between the lower QC and higher QC means from the stored samples in relation to the nominal value, the analyzed compounds remained stable during that period, since the deviations found were in alignment with the established criteria.

Stability analyses were carried out with a primary solution of higher concentration and a work solution of lower concen- tration for each analyte and its respective IS. The results were evaluated comparing the individual areas of analyte and the individual areas of IS. Comparing the mean values of analyte and IS responses for the solutions analyzed after 25:40 hours (UDCA/UDCA D $)$ ), 24:40 hours (GUDCA/GUDCA $\mathrm{D}_{4}$ ), and 22:00 hours (TUDCA/TUDCA $\mathrm{D}_{4}$ ) maintained at room temperature and samples analyzed after 29,18 , and 26 days kept under refrigeration, for each analyte and its IS, respectively, with the means obtained from freshly prepared solutions, it can be concluded that the solutions were stable, since the deviations found were less than $10 \%$.

\section{Conclusion}

After all those tests, it was concluded that the analytical method was successfully developed and validated, since it did not present matrix effect and residual effect, proving to be selective for the molecules under study, with adequate accuracy and precision. Accordingly, the method was sensitive, having a coefficient of variation less than $20 \%$ for the LLOQ of each compound. In this way, the method can be applied in bioequivalence studies to determine ursodiol and its metabolites in a reproducible, simple, and effective way.

\section{Author contributions}

$\mathrm{MCP}, \mathrm{DCB}, \mathrm{ACdO}, \mathrm{CML}$, and SACC made equal contributions to the design and implementation of the research, to the analysis of the results, and to the writing of this manuscript. All authors contributed to data analysis, drafting and revising the article, gave final approval of the version to be published, and agree to be accountable for all aspects of the work.

\section{Disclosure}

The authors report no conflicts of interest in this work.

\section{References}

1. The ALSUntangled Group. ALSUntangled no. 25: ursodiol. Amyotroph Lateral Scler Frontotemporal Degener. 2014;15(5-6):475-478.

2. Tonin F, Arends I. Latest development in the synthesis of ursodeoxycholic acid (UDCA): a critical review. Beilstein J Org Chem. 2018;14: 470-483.

3. Tessier E, Neirinck L, Zhu Z. High-performance liquid chromatographic mass spectrometric method for the determination of ursodeoxycholic acid and its glycine and taurine conjugates in human plasma. J Chromatogr B Analyt Technol Biomed Life Sci. 2003;798(2):295-302.

4. Ursacol ${ }^{\circledR}$ [Package Insert]. Santana do Parnaíba, SP (Brazil): CHIESI Pharma Inc, Zambom Lab Pharma Inc; 2015.

5. URSO $250 \AA$ and URSO Forte ${ }^{\circledR}$ [Package Insert]. Bridgewater, NJ: Aptalis Pharma US, Inc; 2013.

6. Ko WK, Kim SJ, Jo MJ, et al. Ursodeoxycholic acid inhibits inflammatory responses and promotes functional recovery after spinal cord injury in rats. Mol Neurobiol. Epub 2018 Mar 20.

7. Thakare R, Alamoudi JA, Gautam N, Rodrigues AD, Alnouti Y. Species differences in bile acids II. Bile acid metabolism. $J$ Appl Toxicol. 2018;38(10):1336-1352. 
8. Horkovics-Kovats S, Ulč I, Vít L, Němec B, Rada V. Physicochemical pharmacokinetics as an optimization tool for generic development: A case study. Eur J Pharm Sci. 2018;111:349-357.

9. Abdel-Ghaffar A, Ghanem HM, Ahmed EK, Hassanin OA, Mohamed RG. Ursodeoxycholic acid suppresses the formation of fructose/streptozotocin-induced diabetic cataract in rats. Fundam Clin Pharmacol. 2018;32(6):627-640.

10. Mroz MS, Lajczak NK, Goggins BJ, Keely S, Keely SJ. The bile acids, deoxycholic acid and ursodeoxycholic acid, regulate colonic epithelial wound healing. Am J Physiol Gastrointest Liver Physiol. 2018;314(3):G378-G387.

11. Shima KR, Ota T, Kato KI, et al. Ursodeoxycholic acid potentiates dipeptidyl peptidase-4 inhibitor sitagliptin by enhancing glucagon-like peptide- 1 secretion in patients with type 2 diabetes and chronic liver disease: a pilot randomized controlled and add-on study. BMJ Open Diabetes Res Care. 2018;6(1):e00469.

12. Pataia V, Papacleovoulou G, Nikolova V, et al. Paternal cholestasis exacerbates obesity-associated hypertension in male offspring but is prevented by paternal ursodeoxycholic acid treatment. Int JObes. Epub 2018 May 24.

13. Sundd Singh S, Shah H, Gupta S, et al. Validation of LC/MS electrospray ionisation method for the estimation of ursodiol in human plasma and its application in bioequivalence study. Ann Chim. 2004;94(12):951-959.

14. BRAZIL. National Health Surveillance Agency. Resolution RDC n. 27, dated May 17, 2012. Provides the minimum requirements for the validation of bioanalytical methods used in studies for registration and post-registration of drugs. Official Gazette of the Federative Republic of Brazil, Brasília, May 2012.
15. BRAZIL. National Health Surveillance Agency. RE n. 899, dated May 29 2003. Guide for validation of Bioanalytical and Analytical Methods. Official Gazette of the Federative Republic of Brazil, Brasília, June 2003.

16. BRASIL. National Health Surveillance Agency. Manual of Good Practices for Bioequivalence and Bioavailability. Brasília; 2002.

17. FDA. Guidance for Industry, Bioanalytical Method Validation, US Department of Health and Human Services, Food and Drug Administration, Centre for Drug Evaluation and Research (CDER). 2013.

18. Matuszewski BK, Constanzer ML, Chavez-Eng CM. Strategies for the assessment of matrix effect in quantitative bioanalytical methods based on HPLC-MS/MS. Anal Chem. 2003;75(13):3019-3030.

19. Kushnir MM, Rockwood AL, Nelson GJ, Yue B, Urry FM. Assessing analytical specificity in quantitative analysis using tandem mass spectrometry. Clin Biochem. 2005;38(4):319-327.

20. Chambers E, Wagrowski-Diehl DM, Lu Z, Mazzeo JR. Systematic and comprehensive strategy for reducing matrix effects in LC/MS/ MS analyses. J Chromatogr B Analyt Technol Biomed Life Sci. 2007;852(1-2):22-34.

21. Sennbro CJ, Knutsson M, van Amsterdam P, Timmerman P. Anticoagulant counter ion impact on bioanalytical LC-MS/MS assays: results from discussions and experiments within the European Bioanalysis Forum. Bioanalysis. 2011;3(21):2393-2399.
Clinical Pharmacology: Advances and Applications

\section{Publish your work in this journal}

Clinical Pharmacology: Advances and Applications is an international, peer-reviewed, open access journal publishing original research, reports, reviews and commentaries on all areas of drug experience in humans. The manuscript management system is completely online and includes a very quick and fair peer-review system, which is all easy to use.

\section{Dovepress}

Visit http://www.dovepress.com/testimonials.php to read real quotes from published authors. 